\title{
$\mathrm{ABO}$ 부적합 수혈에 의한 급성용혈수혈반응: 치명적 증례 보고 및 문헌 검토
}

\author{
임현호 ${ }^{1} \cdot$ 김경희 ${ }^{1} \cdot$ 안규대 $^{1} \cdot$ 정인화 $^{1} \cdot$ 손영기 ${ }^{2}$ \\ 동아대학교 의과대학 진단검사의학교실 ${ }^{1}$, 동아대학교 의과대학 내과학교실 ${ }^{2}$
}

\section{Acute Hemolytic Transfusion Reaction due to ABO-Incompatible Blood Transfusion: A Fatal Case Report and Review of the Literature}

\author{
Hyeon-Ho Lim ${ }^{1}$, Kyeong-Hee Kim ${ }^{1}$, Gyu-Dae An ${ }^{1}$, In-Hwa Jeong ${ }^{1}$, Young-Ki Son ${ }^{2}$ \\ Departments of Laboratory Medicine ${ }^{1}$, Internal Medicine ${ }^{2}$, Dong-A University College of Medicine, Busan, Korea
}

\begin{abstract}
A 77-year-old female patient who was suspected to have had an acute hemolytic transfusion reaction was admitted to the emergency room. She received one unit of type A red blood cells in a type B patient during a total knee arthroplasty operation at another medical institution. ABO-incompatible transfusion was carried out due to an identification error between the patient and blood product. At the time of admission, acute hemolytic reaction, lactic acidosis, and disseminated intravascular coagulation were observed. She was admitted to the intensive care unit and received continuous renal replacement therapy. She maintained renal function and was moved to the general ward on the 7th day. Complications such as pulmonary edema, gastrointestinal bleeding, and ischemic colitis persisted, and the patient died on the 111th after admission. This case is the first report of death due to an ABO-incompatible transfusion in Korea. Efforts to establish a safe transfusion environment are necessary not only at individual medical institutions but also at the national level. (Korean J Blood Transfus 2018;29:73-78)
\end{abstract}

Key words: ABO incompatible transfusion, Hemolytic transfusion reaction, Transfusion safety

\section{서 론}

Landsteiner가 $\mathrm{ABO}$ 혈액형군을 발견하여 수혈 의학의 과학적 기틀을 마련한 이후, 수혈요법은 임상적으로 유용하며 중요한 치료방법으로 발전 되어 왔다. 하지만 의료인의 실수로 인한 $\mathrm{ABO}$ 혈
액형 불일치 수혈(ABO-incompatible blood transfusion)은 주요 수혈 부작용의 하나로 지속적으로 발생되고 있다[1,2]. $\mathrm{ABO}$ 불일치 수혈은 급성용 혈수혈반응을 야기할 수 있으며 입원이나 중환자 실 치료 혹은 사망에까지 이르게 할 수 있다.

2009년 일본에서 설문 조사한 연구에 따르면

Received on February 11, 2018. Revised on March 13, 2018. Accepted on March 14, 2018

Correspondence to: Kyeong-Hee Kim

Department of Laboratory Medicine, Dong-A University College of Medicine, 32 Daeshingongwon-ro, Seo-gu, Busan 49201, Korea Tel: 82-51-240-2850, Fax: 82-51-255-9366, E-mail: progreen@dau.ac.kr, ORCID: http://orcid.org/0000-0002-6694-4296

@) This is an Open Access article distributed under the terms of the Creative Commons Attribution Non-Commercial License (http://creativecommons.org/licenses/by-nc/4.0) which permits unrestricted non-commercial use, distribution, and reproduction in any medium, provided the original work is properly cited.

Copyright (C) 2018 The Korean Society of Blood Transfusion 
1995년부터 2004년까지 ABO 부적합 수혈에 의 해 총 17 명의 예방 가능한 사망이 발생하였고 또 한, $\mathrm{ABO}$ 부적합 수혈의 원인으로는 환자와 혈액 제제의 확인 오류가 가장 흔하며 절반을 차지하 였다고 보고하였다[3]. 국내 수혈부작용 보고 기 구인 한국혈액안전감시체계(Korean Hemovigilance System)에 따르면 2008년 4월부터 2012년 11월까 지 $\mathrm{ABO}$ 부적합 수혈로 인한 급성용혈수혈반응 이 12건 보고되었고 사망보고는 없었다[4]. 1973 년 전혈 수혈 후 급성용혈작용에 의한 사망 1 예 [5]가 보고되어 있으나, 수혈된 혈액의 $\mathrm{ABO}$ 혈액 형이 보고되지 않아 $\mathrm{ABO}$ 부적합 수혈의 여부가 명확하지 않다. 추가로 1978년 김 등[6]이 보고한 $\mathrm{ABO}$ 부적합 수혈에 의한 급성 신부전 치료 경험 을 제외하면 $\mathrm{ABO}$ 부적합 수혈 현황에 대한 체계 적인 문헌 보고가 드물다. 2-2-2 안전수혈 캠페인 [4]과 같은 안전한 수혈에 대한 인식 증가와 교육, 우수검사실 신임인증제도 및 의료 기관인증 평가 에서의 수혈 관련 심사가 강화되었다. 그럼에도 불구하고 $\mathrm{ABO}$ 부적합 수혈에 의한 급성용혈수 혈반응이 사망의 주요 원인이 된 예를 경험하였 기에 안전한 수혈을 위한 체계 확립을 위해 문헌 고찰과 함께 증례를 보고하고자 한다.

\section{증 례}

77세 여자 환자가 급성용혈수혈반응이 의심되 어 응급실을 통해서 전원 되었다. 내원 당시 환자 는 호흡곤란 및 오한을 호소하였고, 황달이 관찰 되었다. 의식은 명료하였고, 생체징후는 혈압 $120 / 70 \mathrm{mmHg}$, 심박수 99 회/분, 호흡수 22회/분, 체온 $37.3^{\circ} \mathrm{C}$ 로 관찰되었다. 당일 타의료기관에서 좌측 슬관절전치환술 수술 중 $\mathrm{B}$ 형 $\mathrm{RhD}$ 양성인 환자에게 $\mathrm{A}$ 형 $\mathrm{RhD}$ 양성 농축적혈구 1 단위가 수 혈되는 실수가 발생하였다. 사고는 혈액제제와
환자 확인 과정의 오류로 인하여 발생하였다. 환 자는 과거 병력상 5 개월 전 담낭절제술을 시행 받았다. 내원 당시 급성용혈반응, 젖산산증(Lactic acidosis), 파종성 혈관내응고(Disseminated intravascular coagulation)의 소견을 보였다. 입원시 환 자의 검사실 소견 중 혈색소혈증(hemoglobine$\mathrm{mia}$, 합토글로빈의 감소, $\mathrm{LDH}$ 의 증가는 급성용 혈성 반응을 시사하였다. 또한 프로트롬빈시간, 활성화부분트롬보플라스틴시간 연장, 섬유소원 분해산물, D-이합체 증가, 섬유소원의 감소는 파 종성 혈관내응고 소견과 일치하였다(Table 1). 내 원 후 바로 중환자실로 입실하여 지속적 신대체 요법(continuous renal replacement therapy)을 시행 하며 신장기능을 보호하였고 $\mathrm{LDH}$ 수치도 3,878 $\mathrm{IU} / \mathrm{L}$ 에서 입원 7일째 $608 \mathrm{IU} / \mathrm{L}$ 로 감소하여 일반 병동으로 이동하여 치료를 지속하였다. 주요 혈 청학적 소견은 내원 1 일째 시행한 직접항글로불 린검사(Direct antiglobulin test, DAT)는 $\operatorname{IgG}$ 에서 2

Table 1. Laboratory findings at admission

\begin{tabular}{lcc}
\hline Test & $\begin{array}{c}\text { Patient } \\
\text { Value }\end{array}$ & $\begin{array}{c}\text { Reference } \\
\text { range }\end{array}$ \\
\hline Hematocrit $(\%)$ & 30.9 & $33 \sim 44$ \\
Hb (g/dL) & 10.3 & $11 \sim 15$ \\
Plasma hemoglobin (mg/dL) & 162.0 & $0 \sim 5$ \\
Haptoglobin (mg/dL) & 32 & $30 \sim 200$ \\
PT (sec) & 34.6 & $10.8 \sim 14.0$ \\
PT $(\%)$ & 20.3 & $70 \sim 130$ \\
PT (INR) & 2.98 & $0.85 \sim 1.20$ \\
APTT (sec) & 87.3 & $21 \sim 32.4$ \\
Fibrinogen (mg/dL) & 43.4 & $200 \sim 400$ \\
Antithrombin III $(\%)$ & 52.7 & $70 \sim 130$ \\
FDP ( $\mu$ g/mL) & $>80.0$ & $0 \sim 5.0$ \\
D-dimer $(\mu \mathrm{g} / \mathrm{mL} \mathrm{FEU)}$ & $>35.0$ & $0 \sim 0.55$ \\
LDH (IU/L) & 3878 & $120 \sim 520$ \\
Creatinine $(\mathrm{mg} / \mathrm{dL})$ & 1.07 & $0.7 \sim 1.0$ \\
\hline
\end{tabular}

$\mathrm{Hb}$, hemoglobin. 
,$+ \mathrm{C} 3 \mathrm{~d}$ 에서 $+/$ 로 약양성 결과를 보였고 2일 뒤 음성으로 전환되었다. 내원 17일째 항-A 동종응 집소가 1:512까지 상승하였으나 이 후 점차 감소 하였다(Table 2). 수혈은 입원 초기 혈구형검사와 혈청형검사가 일치하지 않는 $\mathrm{ABO}$ 불일치를 보 여 적혈구제제는 $\mathrm{O}$ 형, 혈소판 및 혈장제제는 $\mathrm{AB}$ 형으로 수혈하였고, $\mathrm{B}$ 형으로 완전히 전환된 이후 내원 60 일에 환자의 혈액형인 B형으로 수혈을 시 행하였다. 환자에게 투여된 총 혈액량은 $\mathrm{O}$ 형 $\mathrm{RhD}$ 양성 적혈구제제 18 단위, $\mathrm{B}$ 형 $\mathrm{RhD}$ 양성 적혈 구제제 9단위, $\mathrm{AB}$ 형 신선동결혈장 10단위, $\mathrm{B}$ 형 신선동결혈장 33단위, $\mathrm{AB}$ 형 농축혈소판 26단위, $\mathrm{B}$ 형 농축혈소판 40 단위, $\mathrm{AB}$ 형 성분채집혈소판 2 단위, $\mathrm{AB}$ 형 동결침전제제 8단위, $\mathrm{B}$ 형 동결침전 제제 8단위이었다. 급성용혈수혈반응에 따른 신 장 손상, 파종성 혈관내응고는 회복되었지만 폐 부종, 위장관 출혈, 허혈성 대장염, 경련 발작 등 의 합병증이 지속적으로 발생하여 내원 111 일에
사망하였다.

\section{고 찰}

본 증례는 $\mathrm{ABO}$ 부적합 수혈에 의한 급성용혈 수혈반응에 따른 합병증으로 환자가 사망한 국내 첫 문헌보고이다. $\mathrm{B}$ 형의 환자에게 실수로 $\mathrm{A}$ 형 적 혈구가 수혈된 후 급성용혈수혈반응의 전형적인 임상 소견과 검사실적 소견이 관찰되었다. 용혈 성수혈반응의 초기에 혈구형검사와 혈청형검사 가 일치하지 않는 $\mathrm{ABO}$ 불일치를 보였기 때문에 $\mathrm{O}$ 형 적혈구와 $\mathrm{AB}$ 형 혈장제제를 사용하였다. $\mathrm{ABO}$ 불일치(mismatched) 혈액제제의 수혈에 따 른 혼란을 최소화하고자 $\mathrm{B}$ 형 적혈구와 혈장제제 의 수혈은 내원 60 일째에 시행되었다.

$\mathrm{ABO}$ 부적합 수혈에 의한 사망 사고는 국내에 서는 문헌 보고가 없었지만, 외국에서는 수혈로 인한 사망사고의 가장 흔한 원인 중의 하나로 많

Table 2. Serologic findings after an erroneous transfusion of a unit of blood group A RBC into B patient

\begin{tabular}{|c|c|c|c|c|c|}
\hline \multirow{2}{*}{ Serologic test } & \multicolumn{5}{|c|}{ Days after transfusion of $\mathrm{ABO}$-incompatible $\mathrm{RBCs}^{*}$} \\
\hline & 1 & 3 & 17 & 32 & 55 \\
\hline \multicolumn{6}{|l|}{ Patient RBCs } \\
\hline \multicolumn{6}{|l|}{ ABO grouping } \\
\hline Anti-A & $1+$ & & Negative & Negative & Negative \\
\hline Anti-B & $4+$ & & $+{ }^{-}$ & $+1-$ & $1+$ \\
\hline \multicolumn{6}{|l|}{ DAT } \\
\hline polyspecific & $1+$ & Negative & Negative & $1+$ & $+{ }^{-}$ \\
\hline $\operatorname{IgG}$ & $2+$ & & & $+1-$ & $+{ }^{-}$ \\
\hline $\mathrm{C} 3 \mathrm{~d}$ & $+1-$ & & & Negative & Negative \\
\hline \multicolumn{6}{|l|}{ Patient serum } \\
\hline \multicolumn{6}{|c|}{ Reverse grouping } \\
\hline A cell & $+{ }^{-}$ & & $4+$ & $4+$ & $4+$ \\
\hline B cell & Negative & & Negative & Negative & Negative \\
\hline Titer of anti-A & $1: 1$ & & $1: 512$ & $1: 256$ & $1: 64$ \\
\hline
\end{tabular}

*The transfusion of type B red blood cell and type B fresh frozen plasma were performed on the 60th day of admission. 
은 보고가 있어 왔다. 영국의 수혈부작용 보고체 계인 SHOT (The Serious Hazards of Transfusion)의 20주년 기념 보고에 따르면, 1996년 2005년동안 $\mathrm{ABO}$ 부적합 수혈로 인해 15 건의 사망과 51 건의 심각한 상해가 발생하였고, 2006년 2016년에는 사망과 심각한 상해가 각각 5 건, 29 건으로 감소 하였다고 하였다. 2016년에는 총 3건의 $\mathrm{ABO}$ 부 적합 수혈이 SHOT에 보고가 되었는데 그 중 두 사건에서 의료기관에서 시행하는 첫 번째 수혈의 경우에는 $\mathrm{ABO}$ 혈액형 검사용 검체와 교차시험 용 검체를 분리하여 두 번의 채혈을 실시하는 것 이 지켜지지 않아서 다른 환자의 혈액을 채혈하 여('wrong blood in tube') 발생하였다고 한다[7]. 1990년에서 1999년까지 미국 뉴욕주에서 적혈구 수혈과 관련된 오류를 분석한 결과 $\mathrm{ABO}$ 부적합 과 연관된 오류는 237 건으로 $1 / 38,000$ 의 빈도를 보였다고 하였다. 그 중 111 건(47\%)은 부작용이 발생하고 않았고, 급성용혈수혈반응이 96건(41\%), 기저질환에 의한 사망은 8 건(3\%)의 결과를 보고 하였다[8]. $\mathrm{ABO}$ 부적합 수혈이 발생된 48명 환자 의 임상적 경과를 분석한 연구에서 $50 \mathrm{~mL}$ 이하의 수혈이 이루어진 경우에는 사망이 없었지만, $50 \mathrm{~mL}$ 를 초과한 경우에는 $16.7 \%$ (6/36)에서 사망 하였다고 보고하였다. $\mathrm{ABO}$ 부적합 수혈의 빠른 인지와 수혈의 중단이 $\mathrm{ABO}$ 부적합 수혈에 따른 증상이나 증후를 최소화하고 사망을 예방할 수 있다[9]. 본 증례는 수술실에서 $50 \mathrm{~mL}$ 을 초과하 는 1 단위의 $\mathrm{ABO}$ 부적합 적혈구가 수혈되어 급성 용혈수혈반응이 발생하고 사망에 이르게 되었다.

수혈은 다양한 직종이 참여하고 여러 단계의 연속된 과정에 의해서 이루어지는 의학적 치료방 법이다. 안전한 수혈이 이루어지도록 하기 위해 서 많은 노력을 기울이고 있지만 수혈 오류를 예 방할 수 있는 완벽한 방법은 아직까지 없다. 수혈 은 손목밴드 확인 시스템, 혈액채취과정, 수혈전
검사, 혈액의 불출 및 운반, 수혈전 환자확인 단 계, 수혈 시행의 단계로 이루어지며, 이들 개별 과정은 수혈 오류가 발생할 수 있는 결정적인 단 계들이다[10]. 수혈전 환자확인 단계는 실수가 발 생하면 수혈 오류로 바로 이어질 수 있기 때문에 핵심단계라고 할 수 있다. 수령된 혈액과 수혈 처 방 등 문서를 확인하는 단계와 환자의 손목밴드 나 환자의 등록번호와 혈액을 확인하는 단계로 나뉘어 질 수 있는데 후자가 더욱 중요하다. 본 증례의 오류도 수혈전 환자확인 단계에서 발생하 였다. 일본에서도 설문방식에 의한 $\mathrm{ABO}$ 부적합 수혈의 원인 조사에서 환자와 혈액제제의 확인 오류가 가장 흔하였고 절반을 차지하였다고 보고 하였다[3].

수혈의 안전성을 해칠 수 있는 핵심 실수에 대 한 Maskens 등[11]의 전향적 분석에서 검체 라벨 링 실수가 $37.5 \%$ 로 가장 흔하고, 혈액의 부적절 한 처방이 $28.8 \%$ 를 차지하였다. 이것은 2001년부 터 2005년 기간 동안 미국식품의약국에 보고된 심각한 사고로 이어질 뼌 하였던 수혈('near hit') 의 원인 분석에서 라벨링 실수가 가장 흔하게 나 타난 것과 일치되는 내용이다[9]. 이러한 라벨링 실수는 잘못된 $\mathrm{ABO}$ 혈액형 검사로 이어지게 되 고 부정확한 혈액제제의 수혈('Incorrect blood component transfused', IBCT)에 이르게 된다. 11,570 건의 $\mathrm{SHOT}$ 보고 중에서 $\mathrm{IBCT}$ 가 3,000 여건을 초 과하여 가장 높은 빈도로 보고되는 것[12]과 연관 지을 수 있겠다.

이처럼 수혈 오류의 주된 위험은 의료진에 있 으며, 기본에 충실한 안전수혈 절차를 익히는 것 이 필요하다. '2-2-2 안전수혈 캠페인'은 의료기 관에서의 첫 수혈인 경우 $\mathrm{ABO}$ 혈액형 검사용 검 체와 교차시험용 검체를 각 각 분리하여 채혈( 2 회 채혈), 2 명의 검사자에 의한 독립적 $\mathrm{ABO}$ 혈액 형 검사, 수혈전 환자 확인은 2 명의 의료인이 함 
께 하는 것이다. 이러한 기본적인 절차가 충분히 교육되고 지켜진다면 수혈 오류가 발생하지 않을 것이다. 하지만 이러한 기본적인 절차는 바쁜 임 상 환경에서 쉽게 무시될 수 있다. 이러한 인적 오류(human error)를 예방하기 위해서 최신의 정 보통신 기술(Information Technology)을 수혈 현장 에 적용하는 경우가 증가하고 있다[13-15]. 무선 주 파수 인식을 통한 자동인식기술인 RFID (RadioFrequency Identification) 기술을 수혈의학에 적용 할 때의 가이드라인까지 발표되어 있다[16]. 하지 만 이러한 최신의 기술도 오류를 일으키거나 실 제 도입시 장벽이 있을 수도 있다[17,18]. 기술적 인 적용 외에도 수혈에 참여하는 의료인들의 지 속적인 교육과 평가, 수혈과정의 능동적인 평가, 혈액안전감시체계의 활성화, 수혈관련 질 향상의 업무를 담당하는 수혈안전책임자(Transfusion Safety Officer)를 두고 안전한 수혈 환경을 추구하는 의 료기관들도 있다[19].

수혈은 다단계의 과정을 거치고, 여러 직종의 참여를 필요로 하는 복잡한 의료 행위이다. 수혈 오류를 줄이고 안전한 수혈 환경을 이루기 위한 한 가지의 단일한 방법은 있을 수가 없다. 본 증 례는 $\mathrm{ABO}$ 부적합 수혈에 의한 급성용혈수혈반 응이 사망의 주요 원인이 된 국내 최초의 문헌 보 고이다. 안전한 수혈 환경을 구축하기 위한 노력 은 개별 의료기관뿐만 아니라 국가적 차원의 논 의와 지원이 필요한 시점이다.

\section{요 약}

급성용혈수혈반응이 의심되어 응급실을 통해 서 전원 된 77세 여자 환자는 타의료기관에서 슬 관절전치환 수술 중 $\mathrm{B}$ 형 환자에게 $\mathrm{A}$ 형 농축 적혈 구가 1 단위 잘못 수혈되었다. 사고는 혈액제제와 환자 확인 과정의 오류로 인하여 발생하였다. 내
원 당시 급성용혈반응, 젖산산증, 파종성 혈관내 응고 소견을 보였다. 중환자실로 입실하여 지속 적 신대체요법을 시행하며 신장기능을 보호하였 고 7일째 일반병실로 이동하였다. 급성용혈수혈 반응에 따른 신장 손상, 파종성 혈관내응고는 회 복되었지만 폐부종, 위장관 출혈, 허혈성 대장염 등의 합병증이 지속적으로 발생하여 내원 111일 에 사망하였다. 본 증례는 $\mathrm{ABO}$ 부적합 수혈에 의 한 급성용혈수혈반응이 사망의 주요 원인인 된 국내 최초의 문헌 보고이다. 안전한 수혈 환경을 구축하기 위한 노력은 개별 의료기관뿐만 아니라 국가적 차원의 논의와 지원이 필요한 시점이다.

\section{References}

1. Stainsby D, Russell J, Cohen H, Lilleyman J. Reducing adverse events in blood transfusion. Br J Haematol 2005;131:8-12

2. Myhre BA, McRuer D. Human error - a significant cause of transfusion mortality. Transfusion 2000;40:879-85

3. Fujii Y, Shibata Y, Miyata S, Inaba S, Asai T, Hoshi $Y$, et al. Consecutive national surveys of ABO-incompatible blood transfusion in Japan. Vox Sang 2009;97:240-6

4. Cho D, Hyun J, Ryang DW. Prevention of ABO incompatible blood transfusion: '2-2-2 safe blood transfusion campaign'. Korean J Blood Transfus 2013;24:79-81

5. Kim PK, Cho KH. A case report of acute hemolytic reaction during blood transfusion. Korean J Anesthesiol 1973;6:255-8

6. Kim YL, Kim DK, Kim HS. A clinical experience upon acute renal failure due to mismatched blood transfusion. Korean J Anesthesiol 1978;11:49-54

7. Bolton-Maggs PHB. Serious hazards of transfusion - conference report: celebration of 
20 years of UK haemovigilance. Transfus Med 2017;27:393-400

8. Linden JV, Wagner K, Voytovich AE, Sheehan J. Transfusion errors in New York State: an analysis of 10 years' experience. Transfusion 2000;40:1207-13

9. Janatpour KA, Kalmin ND, Jensen HM, Holland PV. Clinical outcomes of ABOincompatible RBC transfusions. Am J Clin Pathol 2008;129:276-81

10. Heddle NM, Fung M, Hervig T, Szczepiorkowski ZM, Torretta L, Arnold E, et al. Challenges and opportunities to prevent transfusion errors: a Qualitative Evaluation for Safer Transfusion (QUEST). Transfusion 2012; 52:1687-95

11. Maskens C, Downie H, Wendt A, Lima A, Merkley L, Lin $\mathrm{Y}$, et al. Hospital-based transfusion error tracking from 2005 to 2010: identifying the key errors threatening patient transfusion safety. Transfusion 2014;54:66-73; quiz 65

12. Bolton-Maggs PH, Cohen H. Serious Hazards of Transfusion (SHOT) haemovigilance and progress is improving transfusion safety. Br J Haematol 2013;163:303-14

13. Murphy MF, Fraser E, Miles D, Noel S, Staves J, Cripps B, et al. How do we monitor hospital transfusion practice using an end-to-end electronic transfusion management system? Transfusion 2012;52:2502-12

14. Nuttall GA, Abenstein JP, Stubbs JR, Santrach $\mathrm{P}$, Ereth MH, Johnson PM, et al. Computerized bar code-based blood identification systems and near-miss transfusion episodes and transfusion errors. Mayo Clin Proc 2013;88: 354-9

15. Sandler SG, Langeberg A, Dohnalek L. Bar code technology improves positive patient identification and transfusion safety. Dev Biol (Basel) 2005;120:19-24

16. Knels R, Ashford P, Bidet F, Böcker W, Briggs $\mathrm{L}$, Bruce $\mathrm{P}$, et al. Guidelines for the use of RFID technology in transfusion medicine. Vox Sang 2010;98 Suppl 2:1-24

17. Snyder ML, Carter A, Jenkins K, Fantz CR. Patient misidentifications caused by errors in standard bar code technology. Clin Chem 2010;56:1554-60

18. Coustasse A, Cunningham B, Deslich S, Willson E, Meadows P. Benefits and barriers of implementation and utilization of RadioFrequency Identification (RFID) systems in transfusion medicine. Perspect Health Inf Manag 2015;12:1d

19. Dunbar NM, Szczepiorkowski ZM. How do we utilize a transfusion safety officer? Transfusion 2015;55:2064-8 